\title{
Escalas do desenvolvimento desigual na rede de produção da reciclagem fluminense: breve incursão por teorias econômicas baseadas em relações de poder
}

Scales of uneven development in the recycling production network in Rio de Janeiro State: a brief tour through economic theories based on power relationships

Échelles de développement inégal dans le réseau de production de Rio de Janeiro: bref tour d'horizon des théories économiques fondées sur les relations de pouvoir Escalas de desarrollo desigual en la red de producción de reciclaje en el estado del Río de Janeiro: un breve recorrido por las teorías económicas basadas en las relaciones de poder

Uilmer Rodrigues Xavier da Cruz, Luiz Jardim de Moraes Wanderley e Luís Henrique Leandro Ribeiro

\section{(2) OpenEdition}

\section{Journals}

\section{Edição electrónica}

URL: https://journals.openedition.org/espacoeconomia/19534

DOI: 10.4000/espacoeconomia. 19534

ISSN: 2317-7837

Editora

Núcleo de Pesquisa Espaço \& Economia

Refêrencia eletrónica

Uilmer Rodrigues Xavier da Cruz, Luiz Jardim de Moraes Wanderley e Luís Henrique Leandro Ribeiro, «Escalas do desenvolvimento desigual na rede de produção da reciclagem fluminense: breve incursão por teorias econômicas baseadas em relações de poder», Espaço e Economia [Online], 21 | 2021, posto online no dia 19 julho 2021, consultado o 19 julho 2021. URL: http://journals.openedition.org/ espacoeconomia/19534 ; DOI: https://doi.org/10.4000/espacoeconomia.19534

Este documento foi criado de forma automática no dia 19 julho 2021.

Espaço e Economia - Revista brasileira de geografia econômica est mise à disposition selon les termes de la licence Creative Commons Attribution - Pas d'Utilisation Commerciale - Partage dans les Mêmes Conditions 4.0 International. 


\section{Escalas do desenvolvimento} desigual na rede de produção da reciclagem fluminense: breve incursão por teorias econômicas baseadas em relações de poder

Scales of uneven development in the recycling production network in Rio de

Janeiro State: a brief tour through economic theories based on power

relationships

Échelles de développement inégal dans le réseau de production de Rio de Janeiro: bref tour d'horizon des théories économiques fondées sur les relations de pouvoir Escalas de desarrollo desigual en la red de producción de reciclaje en el estado del Río de Janeiro: un breve recorrido por las teorías económicas basadas en las relaciones de poder

Uilmer Rodrigues Xavier da Cruz, Luiz Jardim de Moraes Wanderley e Luís Henrique Leandro Ribeiro

\section{Introdução}

1 A consolidação do capitalismo no último século é responsável pela acentuação do consumo, especialmente de produtos industrializados, que geram uma grande quantidade de resíduos. Diante disso, a sociedade contemporânea se depara, cada vez mais, com estudos relacionados à sustentabilidade, já que os cientistas sociais se veem convocados a refletir sobre os limites de exploração da natureza.

Nas últimas décadas, o manejo de resíduos sólidos despertou o interesse de outros campos, como o da geografia, que costuma abordar os aspectos da catação e da 
reciclagem sob o viés dos impactos socioambientais no espaço urbano e das relações sociais imbricadas nesse processo.

3 Nesse sentido, não se pode deixar de lembrar dos sujeitos sociais que estão envolvidos nas práticas da catação e da reciclagem, uma vez que a geração excessiva de resíduos sólidos, provocada pela superprodução, demanda que alguém trabalhe manejando esses restos. Esse alguém é representado por uma população explorada e marginalizada com baixos rendimentos alcançados com sua força de trabalho, enquanto outros lucram com sua exploração.

4 Assim, é possível constatar que o manejo de resíduos sólidos, que assume a forma de catação/reciclagem, possui um papel importante para o meio ambiente, ainda que reproduza o caráter explorador e excludente sobre a população que realiza esse trabalho, contribuindo, pois, para a manutenção das relações desiguais de poder implícitas e da posição de marginalização desses sujeitos.

5 Nesse seguimento, este $\operatorname{artigo}^{1}$ traz uma revisão bibliográfica na área da ciência geográfica a fim de desvelar as possíveis formas de interpretação teórica do fenômeno da catação e da reciclagem, especialmente na realidade fluminense. A orientação principal é a de que esses fenômenos representam a prática de sujeitos sociais que possuem suas vidas marcadas veementemente pelo funcionamento excludente e explorador do trabalho no sistema capitalista de produção.

6 A discussão deste artigo se divide em três partes. Na primeira, são apresentados dados que contextualizam a cena da catação e da reciclagem no Rio de Janeiro. A segunda parte, contida na seção Catação e as relações de poder, procura refletir sobre a reciclagem enquanto rede de produção, e não apenas de relações sociais, composta por diversos atores que exercem funções diferenciadas na produção dos materiais reciclados. Considera-se, contudo, que, por mais que o poder parta de diferentes pontos da rede e de diferentes atores, haverá circulação desigual de capital, informação e poder entre os participantes, sendo estes ordenados hierarquicamente, mediante a posição social em que se situam. A terceira parte, disposta na seção Catação e as escalas do desenvolvimento geográfico desigual, dialoga sobre a relação direta da catação com a precarização do trabalho e a própria transformação do modo de acumulação capitalista atual. Nesta relação os catadores de materiais recicláveis, que são a parte fundamental da manutenção da produção, representam o elo mais frágil na base da hierarquia, que é composta por catadores, compradores de sucata, atravessadores e empresários da indústria de transformação. Além disso, trata de como o capitalismo necessita dessas relações desiguais para manter seu status, em nome do qual uma população se definha enquanto a outra se expande.

7 Este artigo parte de um levantamento realizado em bases de dados bibliográficas como SciELO, Periódicos CAPES e Google Acadêmico, nas quais foram pesquisadas e consideradas produções que tratavam sobretudo da precarização do trabalho do catador de material reciclável no sistema de produção capitalista. Para além disso, foram pesquisados trabalhos de teóricos da geografia econômica que se aprofundaram na feição espacial do capitalismo, dentre eles Harvey (2011) e Smith (1988), e de estudiosos sociais que enveredaram pelo conceito de rede, como Rosado (2009) e Santos (2006). Por meio dessa pesquisa, torna-se possível, neste artigo, contrapor o conceito de rede com o usual conceito de cadeia de reciclagem, apresentando, nesse seguimento, a catação como parte fundamental da rede de produção da reciclagem. 
8 É válido destacar que a discussão deste artigo procura refletir sobre as posições ocupadas pelos sujeitos sociais marginalizados dentro da lógica de produção capitalista e o pouco acesso desses sujeitos ao consumo, uma vez que possuem trajetórias marcadas pela exploração da mão de obra e pela invisibilização na sociedade.

\section{A cena da catação no Rio de Janeiro}

9 O Instituto Brasileiro de Geografia e Estatística (IBGE) estima que, no Brasil, existiam, em 2010, cerca de 230 mil catadores de materiais recicláveis em atividade. Segundo dados do Governo do Estado, somente no Rio de Janeiro, aproximadamente $50 \mathrm{mil}$ pessoas obtinham seus rendimentos por meio dessa atividade em 2007 (CATADORES..., 2008).

10 Embora represente uma pequena parcela desse montante, que é composto sobretudo por catadores de rua, parte dos trabalhadores da catação é cooperativada. Isto é, tem seu trabalho organizado em cooperativas, integrando uma espécie de rede de comercialização que tem como propósito oferecer benefícios sobre os quais, fora dela, eles não estariam assegurados. Tais cooperativas respondem pela negociação do material coletado. Sua função é, nesse sentido, evitar a exploração dos catadores pelos intermediários, melhorando não só sua renda, mas também suas condições de trabalho (SOUZA; PAULA; SOUZA-PINTO, 2012). Elas exercem, em tese, uma função social, posto que contribuem para a estruturação do trabalho e, consequentemente, para a inserção dos catadores na sociedade como profissionais e cidadãos, dando visibilidade a esses e maximizando a importância de sua atuação, sobretudo no que se refere à manutenção da paisagem urbana (ABREU, 2001).

11 No estado do Rio de Janeiro, existe uma rede composta por 77 cooperativas. Dessas, 33 se situam na Região Metropolitana do Rio de Janeiro (RMRJ), estando elas distribuídas em oito cidades: Rio de Janeiro, Niterói, Nova Iguaçu, São João de Meriti, São Gonçalo, Nilópolis, Duque de Caxias e Mesquita. Essas 33 cooperativas da RMRJ reuniam, segundo levantamento realizado por Ribeiro et al. (2014), 1.284 catadores. Estes produziam, em média, 1.500 toneladas de material reciclável por mês, número este que se converte no valor de R $\$ 536 \mathrm{mil} / \mathrm{mês}$ ou R \$ 6,432 milhões/ano (GERI apud RIBEIRO et al., 2014).

12 Graças à atuação dessas cooperativas no Rio de Janeiro, estima-se a economia de um número considerável de recursos por meio da reciclagem de materiais como metal, alumínio, plástico e papel, os quais são coletados diariamente pelos catadores. A indústria fluminense conseguia poupar, a partir da reciclagem do metal, cerca de $\mathrm{R} \$ 3,4$ milhões. $O$ alumínio gerava uma economia de $\mathrm{R} \$ 1,7$ milhão. Já com o plástico, obtevese algo em torno de $\mathrm{R} \$ 23$ milhões. E, finalmente, com o papel foram $\mathrm{R} \$ 5,9$ milhões. A economia total de recursos girava em torno de $\mathrm{R} \$ 34$ milhões, o que, "do ponto de vista da contribuição per capita, [demonstra que] cada catador [...] foi responsável por $\mathrm{R} \$ 27$ mil poupados para a economia estadual" (RIBEIRO et al., 2014, p. 203), pelo menos no ano que compreende a pesquisa.

13 Com base nesses dados, pode-se dizer que as cooperativas - e aqui não apenas as fluminenses -, exercem também uma função econômica, gerando impacto na estrutura produtiva. Nesse sentido, é inegável que a atividade da reciclagem se conecta com o modo de produção, retroalimentando-o. É essa a hipótese com a qual operamos. O trabalho cooperativado no Rio de Janeiro é apenas uma amostra de como a reciclagem, 
ao cumprir uma função ambiental de reinserção de recursos no sistema produtivo, contribui também para a geração de matéria-prima a ser utilizada na indústria.

\section{Catação e as relações de poder}

14 A prática da reciclagem está diretamente ligada ao modo capitalista de produção. A produção massiva de bens de consumo, que alimenta a lógica de manutenção do capital constante e, por sua vez, o propósito de geração de lucros crescentes para os capitalistas (HARVEY, 2011), está indissociada do descarte excessivo de resíduos sólidos.

Para a indústria da reciclagem, a principal justificativa para o processo de reciclagem de resíduos descartados provém da necessidade de se reutilizar a mesma matéria-prima utilizada em produções anteriores, dada a escassez de material relacionada à exploração constante dos recursos (naturais), seja no presente, seja por projeção de consequências futuras. Torna-se também a possibilidade de atingir lucros em um novo setor de acumulação, aproveitando-se do baixo custo da matéria-prima proveniente da reciclagem de resíduos sólidos urbanos e da baixa remuneração de sua coleta. Ainda funciona como forma de legitimar uma rede de produção baseada nos "descartáveis", uma vez que são caracterizados como "ambientalmente corretos", reduzindo a oposição ou a crítica social.

16 Simultaneamente à necessidade das indústrias de reciclagem de maiores taxas de lucro, há a exploração do trabalho de catadores, responsáveis pela coleta de resíduos sólidos urbanos, e também a incorporação de novas tecnologias, que diminuem o custo de produção e circulação dos materiais recicláveis. Dessa maneira, colabora-se $e^{2}$ para a manutenção do ciclo da mais-valia e, por sua vez, para a acumulação de capital.

0 trabalho de catadores de materiais recicláveis está ligado à luta pela sobrevivência desses indivíduos. A ausência de alternativas de trabalho formal, por sua vez, impedeos de acesso a determinadas esferas sociais intrínsecas à sociedade de classes. Para além disso, sua prática laboral cotidiana pode ser interpretada a luz da questão ambiental coleta seletiva de resíduos sólidos urbanos e a destinação correta desses resíduos, como destacou Rosado (2009).

Rosado (2009), em seu olhar sobre a realidade socialmente invisibilizada dos catadores e, mais a fundo, catadoras de lixo, afirmou que, apesar da estratégia de sobrevivência desses sujeitos que se valem da catação como fonte de renda, eles sofrem uma exposição exacerbada, em seu cotidiano, a um ciclo de exploração que os coloca em condição de marginais nas redes de relações sociais que envolvem a reciclagem. Segundo a autora, "podemos definir as redes sociais como um sistema aberto em permanente construção, que se tecem e entretecem individual e coletivamente" (ROSADO, 2009, p. 34).

19 Rosado (2009) ainda afirma que a rede de reciclagem constitui uma esfera na qual trajetórias cotidianas se inter-relacionam

[...] pelas conexões entre as pessoas que ocupam posições no jogo do lixo, no qual os distintos atores interagem, tendo cada nó uma posição específica e interdependente das demais no complexo campo do lixo, vivenciando um conjunto de relações econômicas, sociais, políticas e culturais que dele emergem. (ROSADO, 2009, p. 34)

$\mathrm{Na}$ compreensão do conceito utilizado pela autora, se compreende as redes como relações de poder, constituídas por trocas de informações que contém significados, que 
se materializam nos enlaces produzidos pelos e entre os atores, por meio de diferentes sistemas de comunicação. Por sua vez, permite-se concomitantemente a circulação desses significados, a partir das práticas espaciais materializadas no cotidiano. Tal relação entre rede e poder também é destacada por Raffestin (1993), que afirma que

É conveniente, pois, decifrar as redes por meio de sua história e do território no qual estão instaladas, por meio dos modos de produção que permitiram a sua instalação e das técnicas que lhes deram forma. As redes são não somente a exibição do poder, mas são ainda feitas à imagem do poder. (RAFFESTIN, 1993, p. 209)

21 Assim como Raffestin (1993), Rosado (2009) compreende a rede enquanto parte integrante de um território, espaço constituído por e a partir de relações de poder (SOUZA, 2003). Desse modo, é compreensível que uma rede social de reciclagem, como trata Rosado (2009), contenha conflitos, que partem de diferentes atores que constituem a lógica da produção da reciclagem.

22 Segundo Foucault (1995), o conceito de poder refere-se a um agrupado de práticas e ações que são correspondentes umas às outras. Para o filósofo, não se trata de um exercício unilateral de alguém sobre algo ou outro alguém, mas de um conjunto de ações que partem de diferentes polos, ou seja, que não ocorrem de maneira unidirecional e dependem da aceitação e/ou resistência dos diferentes atores que constituem as relações sociais.

Como elucida Silva (2017), sobre a necessidade de trazer à tona os discursos dos principais atores da rede de reciclagem, tal relação de trabalho, por vezes, é tensionada a partir do empoderamento dos catadores. Lussari (2016) chega a uma compreensão que vai além da ideia de que as cooperativas são importantes para o empoderamento dos trabalhadores relacionados à coleta seletiva; porém, caminha no entendimento de que transformar a força de trabalho individual em coletiva colabora para o fortalecimento do discurso dos trabalhadores perante a rede de reciclagem. Conforme destaca,

Ao discutir-se a emergência de uma cultura organizacional em uma cooperativa de recicladores de resíduos sólidos, cujos cooperados são oriundos de um estado de trabalho diferente do necessário, para se estabelecer na nova ocupação, há a necessidade de se entender todo o contexto histórico, social e político, de forma a estabelecer um lugar, um território e um espaço, em que se crie uma nova identidade do trabalhador. (LUSSARI, 2016, p. 184)

Como demonstram não apenas Dagnino e Dagnino (2010), como também Costa e Chaves (2012) e Bosi (2008), a organização dos catadores envolvidos na rede de produção da reciclagem de resíduos sólidos urbanos, através de cooperativas, insere-se no campo de lutas para a visibilidade dos trabalhadores da catação. Lutas essas direcionadas, inclusive, ao fomento de políticas públicas que envolvam esses sujeitos.

Nossa proposta, todavia, reside em compreender a reciclagem enquanto uma rede de produção, e não apenas de relações sociais, composta por diversos atores que exercem funções diferenciadas na produção dos materiais reciclados, mas que ao mesmo tempo tesem laços sociais e políticos. Considera-se, contudo, que, por mais que o poder parta de diferentes pontos da rede e de diferentes atores, haverá circulação desigual de capital, informação e poder entre os participantes, ordenando-os hierarquicamente.

o fato é que as redes de produção da reciclagem se realizam em diversas escalas geográficas (global, nacional, regional e urbana), nas quais a lógica de acumulação da indústria de reciclagem se (re)produz, e têm relação direta com a situação econômica, 
política e espacial dos sujeitos e atores em diferentes cidades (escala intra-urbana), particularmente nas cidades dos países com elevado grau de pobreza. Assim, afirma Rosado (2009) que a posição de mediado e mediador na rede de reciclagem depende justamente da compreensão discursiva dos sujeitos que constituem tal rede, ou seja, da condição social na qual os sujeitos se encontram. Em seus termos,

Não podemos partir do pressuposto que todos os agentes envolvidos (mediadores e mediados) possuem a mesma condição de entendimento, pois o mediador assume esse papel, justamente, pela dificuldade do mediado em relacionar-se com outros jogos de linguagem, ou seja, o mediador somente tem razão de existir na relação se for para cumprir este papel. [...] É mais interessante para o grupo social que o mediador atribua validade ao seu discurso (em diferentes meios) e que procure traduzi-lo no discurso do outro. Assim, na prática mediadora, pode-se perceber uma "violência simbólica" pela subjugação da cultura, do entendimento acerca do mundo, do próprio mediado. (ROSADO, 2009, p. 110)

27 A posição da autora supracitada colabora para a compreensão de que haverá, em uma rede de reciclagem, práticas e ações desiguais entre os atores, mediante a posição social em que esses se situam. Os catadores de materiais recicláveis, em particular os catadores de ruas, constroem suas vivências na condição de sujeitos subordinados aos atravessadores, na ausência de cooperativas ou galpões de reciclagem de resíduos sólidos urbanos, ainda que nessas últimas contemplem outro tipo de relação de poder.

\section{Catação e as escalas do desenvolvimento geográfico desigual}

28 As desigualdades sociais são alvo sistemático de pesquisas em diversas áreas das ciências sociais. No entanto, buscaremos, no aporte teórico da geografia, a compreensão da produção histórica e geográfica das desigualdades no capitalismo em sua relação com o desenvolvimento geográfico desigual no âmbito da rede de produção da reciclagem.

Com relação à escala nacional de atuação da indústria da reciclagem no Brasil, Pereira et al. (2016) discutem sobre o impacto na economia do país, em sua interface com o mercado exportador. Os autores demonstraram a importância da manutenção da prática de reciclagem para a segurança da economia brasileira ao se referirem à sucata de alumínio, principal produto do setor no país. O destaque do alumínio reside no valor mais elevado pago por ele, em comparação com outros materiais recicláveis, como plástico e papel.

Os autores apontaram que o país se encontrava em uma situação avançada no contexto mundial da reciclagem de alumínio, tendo, em meados dos anos 2000, ultrapassado os $95 \%$ de reciclagem desse material produzido no mercado interno. Isso aponta para uma relação direta entre a compra da sucata e a produção do alumínio no Brasil, consolidando um sistema de produção em rede. No entanto, quando perpassado pelo valor de repasse à base da cadeia/rede de reciclagem, ainda existe uma remuneração baixa, em detrimento de valores mais elevados auferidos por atores que ocupam posições hierarquicamente superiores na rede de produção, como atravessadores e empresários.

31 Pereira et al. (2016) destacaram os efeitos diretos (negativos) da crise econômica de 2008-2009 na rede de produção da reciclagem brasileira. Os mesmos efeitos dos 
processos econômicos globais sobre o mercado nacional de reciclados foi constatado por Costa, para quem

A crise econômica, que assolou o mundo em 2009, afetou incisivamente o mercado de recicláveis; em especial, o mercado de metais, rebaixando os valores pagos aos catadores de sucata, uma vez que a indústria deu preferência à utilização de matérias-primas virgens no processo produtivo, a exemplo do ferro-gusa. (COSTA, 2014, p. 52)

Tal consequência é defendida pelos autores como resultado da queda nas exportações brasileiras de produtos metalúrgicos e, por suposto, do excesso de matérias-primas in natura no mercado nacional, reduzindo assim o valor da sucata dos catadores. Segundo Costa e Chaves (2012), o trabalho de catação tem ligação direta com as características do capitalismo contemporâneo, mais especificamente com as mudanças nas configurações desse sistema e do fenômeno do trabalho nas últimas décadas. Em suas palavras,

Observa-se nas ciências sociais e humanas a necessidade de compreender o fenômeno do trabalho no lixo, a partir do questionamento sobre o papel dos trabalhadores catadores na indústria da reciclagem, questões profícuas, como a reinserção do lixo na lógica capitalista de produção, a luta de classes via ampliação da pobreza e negação ao acesso ao mundo do trabalho têm sido (re)pensados no contexto da dinâmica estratégica da reprodução ampliada do capital. (COSTA e CHAVES, 2012, p. 2)

Os autores assumem a necessidade de abordagens acerca das relações sociais de trabalho no que tangem ao sistema capitalista de produção da reciclagem. Desse modo, definem seu recorte analítico na compreensão da posição dos catadores no interior da rede de produção da reciclagem. Destacam ainda a relação direta da catação com a precarização do trabalho e a própria transformação do modo de acumulação capitalista atual, destacando um incremento de aproximadamente $240 \%$ dos trabalhadores do setor de reciclagem no Brasil entre 1995 e 2005. Segundo Costa e Chaves (2012, p. 3), o crescimento do número de catadores assegura "a sustentabilidade do processamento industrial dos materiais, garantindo maior ganho via exploração do trabalhador, diminuição do uso de matérias-primas, economia de energia e, consequentemente, maximização dos lucros".

No entanto, a posição desses profissionais na rede de produção da reciclagem representa o elo mais frágil na base da hierarquia, que compreende, em ordem crescente, catadores, compradores de sucata, atravessadores e empresários da indústria de transformação. É interessante perceber que, embora a rede de produção da reciclagem seja transpassada por vários atores, os catadores de materiais recicláveis constituem a parte principal da manutenção da produção e a possibilidade de realização de altas taxas de lucro pelos agentes capitalistas nos países periféricos.

Montenegro (2012) e Costa e Chaves (2012) afirmam que a situação social dos catadores é materializada em precárias condições de trabalho, resultantes da busca constante por estratégias de sobrevivência. Esse é o mesmo argumento de Bosi (2008), para o qual os catadores são sujeitos excluídos socialmente ${ }^{3}$, que buscam formas alternativas de produzir renda. Para o autor, o massivo aumento de trabalhadores cujo ofício refere-se ao trabalho informal da catação está diretamente associado ao aumento de desemprego no setor formal, o que leva os trabalhadores excluídos a buscarem na catação uma possibilidade de renda. 
Buscando dialogar com a proposta teórica de Harvey (2011), é possível compreender a rede de produção da reciclagem de lixo enquanto pertencente ao ciclo de acumulação de capital constante. Ao discutir o que denominou de "enigma do capital", Harvey produz uma reflexão acerca do modo como o capital se mantém e se reproduz segundo uma lógica de acumulação constante, concentrada nas classes mais abastadas, em detrimento da espoliação das classes subalternizadas. 0 autor afirma que, ao longo da história do capitalismo, para a manutenção do crescimento econômico, novos padrões e práticas foram estabelecidos entre os atores que compõem espacialmente as redes desiguais de poder.

Desse modo, uma das formas apontadas por Harvey (2011), a partir de Marx, para a elevação das taxas de lucro para a acumulação de capital constante é a alteração de postos e condições de trabalho e, por suposto, a diminuição de ofertas de emprego e a ampliação de um exército industrial de reserva. Os trabalhadores, além de ficarem à deriva, sob condições de pobreza, são impelidos a competir entre si pela ocupação de escassas vagas de emprego ou mesmo subempregos, com remunerações mais baixas e mais precárias. Quando não é possível sua alocação profissional formal, os trabalhadores excluídos, em busca da sobrevivência, passam a criar novas práticas de trabalho e geração de renda, como é o caso da catação de resíduos sólidos urbanos.

O diálogo proposto por Harvey (2011) contribui para a noção de trabalhadores excluídos, apresentada por Bosi (2008). A paradoxal prática informal do trabalho, apesar de não compor o circuito superior da acumulação do capital, contribui, ainda que paralela e indiretamente, por meio da captura do mais valia decorrente do trabalho precário informal. Se, por um lado, os sujeitos excluídos integram o exército industrial de reserva na briga por emprego no setor formal e forçam a base salarial para baixo, por outro, eles colaboraram para a reprodução do capital, ofertando serviços baratos enquanto catadores, fazendo retornar matéria-prima a partir de resíduos sólidos para a indústria da reciclagem, e agindo como consumidores de bens de primeira necessidade, tais como alimentos e produtos de higiene (ainda que de maneira bastante limitada).

Destarte, faz-se necessário o debate sobre o sistema capitalista de produção e suas diferenças socioespaciais, visto que é de grande valia à teoria do desenvolvimento desigual de Smith (1993). Para esse autor, para que a expansão do capitalismo se imprima de maneira constante e para que corresponda à ânsia por acúmulo progressivo de capital, é inevitável e estratégico que se estabeleça uma lógica de desenvolvimento desigual. Ora, o que o autor afirma é que, ao passo que há crescimento econômico de determinada faixa populacional, outra faixa populacional se definha, por meio da exploração ou da exclusão.

Do mesmo modo, Harvey (2011) aponta a intensificação de um processo de desemprego atrelado à necessidade de aumento ou manutenção da taxa de lucro, o que inevitavelmente produz transformações espaciais. Ao propor o desenvolvimento espacialmente desigual, Smith explica que o desenvolvimento de um lugar está associado ao empobrecimento de outro. Desse modo, podemos considerar os trabalhadores excluídos que compõem, como catadores, a rede de produção da reciclagem do estado do Rio de Janeiro o reflexo do desenvolvimento desigual capitalista.

No caminho de compreender o fenômeno da desigualdade, fruto da produção da reciclagem, Ross, Carvalhal e Ribeiro (2010) afirmam que 
[...] notamos as formas estratégicas do capital na exploração do trabalho dos catadores de materiais recicláveis, constatando a perversidade engendrada pelos processos reprodutivos do capital. A condição de precariedade é estrutural da sustentação econômica do circuito da reciclagem, como corolário da falta de alternativas para os trabalhadores, que a tal condição "devem" se submeter. (ROSS; CARVALHAL; RIBEIRO, 2010, p. 118)

Como discutiram os autores destacados, analisar as relações de trabalho e a exploração dos trabalhadores da coleta seletiva colabora para a compreensão da organização desigual do espaço, a partir das relações informais de trabalho que perpetuam a lógica de segregação espacial. Vale destacar, segundo Corrêa (2000), que o espaço é resultante das relações sociais (também intrínsecas às relações de trabalho), como também é elemento fundamental para a manutenção dessas mesmas relações. Assim, as condições simultâneas para a manutenção dessas relações estão relacionadas à existência da própria configuração espacial, de maneira dialética.

Assim, compreender de que modo os principais atores que vivenciam o espaço da reciclagem animam a rede de produção significa entender como se estabelecem as relações sociais e de trabalho entre atores, no âmbito de um ordenamento espacial em rede. Ou seja, como ponto de partida, é necessária uma reflexão direta sobre a prática de catação e os trabalhadores que realizam tal prática laboral. Nesse seguimento, Ross, Carvalhal e Ribeiro (2010) assinalam que

Esses trabalhadores exercem essa atividade de catação informalmente, isto é, sem os atributos legais de um trabalhador registrado formalmente, o que é uma dimensão importante da precariedade, já que estão desprotegidos das inseguranças que atingem a atividade (sem renda mínima garantida e proteção contra acidentes ou problemas de saúde). Além do mais, são intrinsecamente subordinados, pois vendem a sua força de trabalho às indústrias de reciclagem (atravessadores) que os exploram. Esses catadores exercem essa função de trabalho sem receber de volta os benefícios sociais do mundo do trabalho, como foi dito anteriormente, além de ser um trabalho exaustivo, com longas horas diária de trabalho na catação. (ROSS; CARVALHAL; RIBEIRO, 2010, p. 119)

Do mesmo modo que um trabalhador do setor formal compõe as relações de trabalho, enquanto subordinado aos proprietários dos meios de produção, o trabalhador informal (catador de rua, que, nesse caso, relaciona-se com a indústria da reciclagem por intermédio de atravessadores), dada a ausência de amparo pelas legislações trabalhistas, se estabelece numa relação ainda maior de exploração, permitindo uma maximização do mais valia capturado a por meio da superexploração do trabalho. Ross, Carvalhal e Ribeiro (2010) concluem sua reflexão afirmando que

[...] a organização dos trabalhadores catadores não significa uma liberdade do metabolismo do capital, pois, para o sistema capitalista, é proveitoso na sua reprodução e ampliação em que haja o trabalho informal e precário. Neste entorno, fazem-se necessárias políticas públicas, garantindo a inserção social dos trabalhadores catadores, objetivando melhores condições de vida. Essas atitudes se identificam através de cooperativas que se configuram em estruturas organizacionais que podem obter a inclusão justa dos trabalhadores e de modo não tão perverso. (ROSS; CARVALHAL; RIBEIRO, 2010, p. 130)

No trecho supracitado, o tensionamento das relações de trabalho que envolvem os atores na rede de produção da reciclagem não garante a inclusão justa desses sujeitos catadores, exigindo ainda um amplo arcabouço jurídico de direitos sociais, bem como políticas públicas direcionadas. 
Este artigo procurou analisar a ligação do desenvolvimento geográfico desigual com a
rede de produção da reciclagem e as relações sociais advindas desse meio. Além disso,
evidenciou-se as relações de poder e as desigualdade existentes em nessa rede de
produção, na qual trabalhador-catador se constitui como elo mais frágil na hierarquia.
Assim, o artigo abordou a importância de se refletir sobre as relações sociais de

Este artigo procurou analisar a ligação do desenvolvimento geográfico desigual com a
rede de produção da reciclagem e as relações sociais advindas desse meio. Além disso,
evidenciou-se as relações de poder e as desigualdade existentes em nessa rede de
produção, na qual trabalhador-catador se constitui como elo mais frágil na hierarquia.
Assim, o artigo abordou a importância de se refletir sobre as relações sociais de

Este artigo procurou analisar a ligação do desenvolvimento geográfico desigual com a
rede de produção da reciclagem e as relações sociais advindas desse meio. Além disso,
evidenciou-se as relações de poder e as desigualdade existentes em nessa rede de
produção, na qual trabalhador-catador se constitui como elo mais frágil na hierarquia.
Assim, o artigo abordou a importância de se refletir sobre as relações sociais de

Nesse sentido, Dagnino e Dagnino (2010) discutem iniciativas reais que poderiam ser adotadas por gestores públicos e, não obstante, no fomento de políticas públicas. Para que se firmem políticas públicas e legislações, que se definam arranjos em prol dos direitos dos trabalhadores envolvidos na rede de produção da reciclagem, é necessário que se leve em consideração os interesses da sociedade atual e futura. Ao retomar as contribuições de Dagnino e Dagnino (2010), pode-se compreender que tais políticas públicas devem corresponder aos interesses dos atores que compõem o jogo do lixo. Não obstante, a posição social de exclusão, na qual se inserem, tem relação direta com o alcance ou o não alcance das políticas públicas pleiteadas.

De maneira contraditória à precarização do trabalho e à geração de uma ampla massa de desempregados, Harvey (2011) destaca que o capitalismo necessita constituir um mercado consumidor para as mercadorias produzidas. Assim, a classe trabalhadora, ao mesmo tempo que é explorada através do trabalho, extraindo a mais-valia absoluta ou relativa, atua como consumidora, retroalimentando a circulação de mercadorias, favorecendo o capitalista de duas formas: através da compra de mercadoria produzida, dando-lhe lucro direto, e através de sua força de trabalho explorada. Sendo assim, o autor destaca que o trabalhador é essencial para a manutenção de lucro e do próprio sistema capitalista.

Deste modo, por se tratar de um sistema de produção capitalista, este corresponde a uma lógica espacial que posiciona os sujeitos espacialmente segundo o poder condicionado ao acúmulo de capital. A prática de coleta seletiva e toda sua rede desigual é, desse modo, retroalimentada pela lógica do capitalismo e do favorecimento de apenas uma parcela da sociedade.

Os autores trazidos para nessa compreensão teórica da catação ajudam a evidenciar que a rede de produção da reciclagem corresponde a um componente importante na lógica capitalista do espaço periférico, na paradoxal relação entre o desenvolvimento econômico de determinada classe e a invisibilidade de outra. Como traduz Santos (2006), a manutenção do circuito superior da economia depende da exploração do circuito inferior. Sendo assim, são produzidas estratégias para que se mantenha esse padrão de acumulação, expressa na relação desigual entre os nós que compõem a rede.

\section{Conclusão} trabalho, compreendendo especificamente a posição dos catadores no sistema capitalista de produção da reciclagem. A elevada exploração e utilização dos recursos naturais, que tendem ao esgotamento, tornam a reciclagem em mercado e o lixo em mercadoria, o que automaticamente se consolida como uma nova oportunidade de geração de lucro para as empresas. Análise aqui empreendida se desenvolveu a partir da cena da catação no estado do Rio de Janeiro.

52 Foi possível compreender a reciclagem como rede de produção composta por múltiplos agentes exercendo diversas funções no tecido produtivo dos materiais reciclados. 
Considerou-se, inclusive, a circulação desigual de capital, informação e poder entre os membros, em uma perspectiva hierárquica.

Além disso, buscou-se dialogar sobre a relação direta entre a catação, a precarização do trabalho e a própria transformação do modo de acumulação capitalista contemporâneo, que faz com que os catadores de materiais recicláveis, que são a parte principal da manutenção da produção, sejam marginalizados na base da hierarquia, composta por catadores, compradores de sucata, atravessadores e empresários da indústria de transformação. Ademais, discutiu-se como o capitalismo necessita dessas relações desiguais para a manutenção do status quo dos grupos hegemônicos.

Nesse seguimento, é possível concluir que, ao mesmo tempo em que os catadores de material reciclável compõem o elo mais frágil da rede de produção da reciclagem, ou do "jogo do lixo", a inexistência desses trabalhadores corresponderia à inexistência da rede como ela se constitui hoje, particularmente sob o aspecto da realidade periférica brasileira.

Obviamente, esta contribuição demonstra a necessidade de maior debate sobre o recorte temático específico da catação a partir das teorias da Geografia Econômica. Pelo contrário: como demonstrado anteriormente, representa uma reflexão para um tema ainda emergente na Geografia, que pode colaborar para compressão das relações sociais e de trabalho da realidade brasileira, em especial dos circuitos produtivos urbanos. Além disso, a proposta buscou reforçar, através da academia, a necessidade de olhar para determinados sujeitos excluídos e invisíveis na sociedade brasileira, no sentido de desvendar o sistema de opressão e caminhar para uma relação mais equilibrada entre atores que compõem sua rede de produção e de poder Moreira (1982).

\section{BIBLIOGRAFIA}

ABREU, M. F. Do lixo a cidadania: estratégia para a ação. São Paulo: UNICEF/Caixa Econômica Federal, 2001.

BOSI, A. P. A organização capitalista do trabalho "informal”: o caso dos catadores de recicláveis. Revista Brasileira de Ciências Sociais, v. 23, n. 67, p. 101-116, 2008.

CATADORES de materiais recicláveis fazem passeata no Rio. Correio Brasiliense, 14 nov. 2008. Disponível em: <https://www.correiobraziliense.com.br/app/noticia/brasil/2008/11/14/internabrasil,48716/amp.html>. Acesso em: 18 nov. 2019.

CORRÊA, R. L. Espaço, um conceito-chave da geografia. In: CASTRO, I. E.; GOMES, P. C. C.; CORREA, R. L. (org.). Geografia: conceitos e temas. Rio de Janeiro: Bertrand Brasil, 2000.

COSTA, W. B.; CHAVES, M. R. Informalidade e precarização do trabalho de catação de materiais recicláveis no Brasil: pontos para debate. In: JORNADA DO TRABALHO, 13, 2012, Presidente Prudente. Anais... Presidente Prudente: CEREST, 2012. 
COSTA, W. B. Os Desafios da Coleta Seletiva e a Organização dos Catadores de Materiais Recicláveis em Caeitité, Bahia. 2014. 141 f. Dissertação (Mestrado em Geografia) - Instituto de Estudos Socioambientais, Universidade Federal de Goiás, Catalão, 2014.

DAGNINO, R. S.; DAGNINO, R. P. Políticas para inclusão social dos catadores de materiais recicláveis. Pegada Especial, p. 65-93, 2010.

FOUCAULT, M. Sujeito e poder. In: DREYFUS, H.; RABINOW, P. Michel Foucault, uma trajetória filosófica: para além do estruturalismo e da hermenêutica. Rio de Janeiro: Universitária, 1995.

HARVEY, D. O enigma do capital: e as crises do capitalismo. São Paulo: Boitempo, 2011.

HENDERSON, J. et. al. Redes de produção globais e a análise do desenvolvimento econômico. Revista Pós Ciências Sociais, v. 8, n. 15, p. 14-170, 2011.

IBGE - INSTITUTO BRASILEIRO DE GEOGRAFIA E ESTATÍSTICA. Censo Demográfico 2010: resultados preliminares do universo - conceitos e definições - tabelas adicionais. Rio de Janeiro: IBGE, 2011.

LUSSARI, W. R. Grupo de Apoiadores e Cooperlix em Presidente Prudente - SP, Brasil. Modelo e Evolução de suas Relações durante Quinze Anos. 2016. 276 f. Tese (Doutorado em Geografia) - Departamento de Geografia, Universidade Estadual Paulista "Júlio de Mesquita Filho", Presidente Prudente, 2016.

MONTENEGRO, M. R. A teoria dos circuitos da economia urbana de Milton Santos: de seu surgimento a sua atualização. Revista Geográfica Venezolana, v. 53, n. 1, p. 147-164, 2012.

MOREIRA, R. A geografia serve para desvendar máscaras sociais. In: MOREIRA, R. (org.). Geografia: teoria e crítica. O saber posto em questão. Petrópolis: Vozes, 1982.

PEREIRA, T. N. D. et al. A reciclagem de alumínio no Brasil e o mercado internacional: uma análise quantitativa. Planejamento e Políticas Públicas, n. 10, 2016.

RAFFESTIN, C. Por uma Geografia do Poder. São Paulo: Ática, 1993.

RIBEIRO, L. C. S. et al. Aspectos econômicos e ambientais da reciclagem: um estudo exploratório nas cooperativas de catadores de material reciclável do Estado do Rio de Janeiro. Nova

Economia, Belo Horizonte, v. 24, n. 1, p. 191-214, 2014.

ROSADO, R. M. Na Esteira do Galpão: catando leituras no território cotidiano da reciclagem do lixo de Porto Alegre/RS. 2009. 333 f. Tese (Doutorado em Geografia) - Departamento de Geografia, Universidade Federal do Rio Grande do Sul, Porto Alegre, 2009.

ROSS, D.; CARVALHAL, M. D.; RIBEIRO, S. Q. A precariedade do trabalho dos catadores de material reciclável no Oeste Paranaense e a dinâmica estratégica da reprodutividade do capital. Pegada, v. 11, n. 2, p. 114-131, 2010.

SANTOS, M. Por uma Geografia das Redes. In: SANTOS, M. A Natureza do Espaço: Técnica e Tempo. Razão e Emoção. São Paulo: EDUSP, 2006.

SILVA, M. C. P. O trabalho dos catadores de materiais recicláveis de Uberaba - MG e a relação com os dois circuitos econômicos da reciclagem. Pegada, v. 18, n. 3, 2017.

SOUZA, L. O. C. A importância histórico-social das Redes. Revista do Terceiro Setor (RETS), jan. 2003.

SOUZA, M. L. O território: sobre espaço e poder, autonomia e desenvolvimento. In: CASTRO, I., E.; GOMES, P. C. ; CORRÊA, R. L. (org.). Geografia: conceitos e temas. Rio de Janeiro: Bertrand Brasil, 1995, p. $77-116$ 
SOUZA, M. T. S.; PAULA, M. B.; SOUZA-PINTO, H. O papel das cooperativas de reciclagem nos canais reversos pós-consumo. Revista de Administração de Empresas, São Paulo, v. 52, n. 2, p. 246-262, 2012.

SMITH, N. Para uma teoria do desenvolvimento desigual: a dialética da diferenciação e da igualização geográficas; para uma teoria do desenvolvimento desigual: a escala espacial e o vaivém do capital. In: SMITH, N. Desenvolvimento Desigual. Rio de Janeiro: Bertrand Brasil, 1988.

\section{NOTAS}

1. Este artigo é resultado da pesquisa As redes de produção da reciclagem do estado do Rio de Janeiro: circuitos espaciais e desafios dos catadores de materiais recicláveis, vinculada à linha de pesquisa em Geografia e Relações de Poder e realizada no curso de Mestrado em Geografia do Programa de Pós-Graduação em Geografia da Faculdade de Formação de Professores da UERJ.

2. A ideia de colaborar para a manutenção do ciclo de mais-valia e para o acúmulo de capital não significa que a atividade de catação não se apresente como, além de força de trabalho que se converte aos interesses do capital, um ato de resistência de sujeitos marginais nas relações sociais que se instituem no sistema capitalista de produção e, por sua vez, nas cidades. Porém, é justificada pela ideia de que, em toda relação social, há uma relação de poder e que, por haver relações de poder (sociais), também há opressão e resistência (entre diferentes sujeitos), como propõe Foucault (1995).

3. É importante destacar que, embora sejam marginalizados socialmente, esses sujeitos são também absorvidos pelo sistema capitalista de produção. Mesmo não estando em situação privilegiada, ainda assim, os catadores contribuem com o giro da engrenagem de poder que os coloca em posição menos favorecida.

\section{RESUMOS}

Este artigo traz a revisão bibliográfica de algumas teorias da Geografia Econômica baseadas em relações de poder que, na área da ciência geográfica, contribuem para desvelar os fenômenos desiguais da catação e da reciclagem. A orientação principal é a de que tais fenômenos influenciam na prática de sujeitos sociais que têm suas vidas marcadas pelo funcionamento excludente e explorador do trabalho no sistema capitalista de produção. À vista disso, este trabalho procura refletir sobre a reciclagem enquanto rede de produção, e não apenas de relações sociais, composta por diversos atores que exercem funções diferenciadas na produção de materiais reciclados. Dialoga ainda sobre a relação direta da catação com a precarização do trabalho, o que faz com que os catadores, protagonistas da manutenção da produção, representem o elo mais frágil da hierarquia composta também por compradores de sucata, atravessadores e empresários da indústria de transformação. Para cumprir essas finalidades, se partiu de um levantamento realizado em bases de dados bibliográficas - SciELO, Periódicos CAPES e Google Acadêmico -, nas quais foram pesquisadas e consideradas produções que tratavam sobretudo da precarização do trabalho do catador de material reciclável no sistema de produção capitalista. Para além disso, dialogamos com teóricos da Geografia Econômica que se 
aprofundaram na lógica capitalista, dentre eles Harvey (2011) e Smith (1988), e de estudiosos sociais que enveredaram pelo conceito de rede, como Rosado (2009) e Santos (2006). Ao fim, se concluiu que, ao mesmo tempo que os trabalhadores representam o elo mais frágil da rede de produção da reciclagem, ou do "jogo do lixo", sem eles a rede não existiria como ela é atualmente concebida, sobretudo no contexto da reciclagem brasileira.

This article is a bibliographic review of some theories of economic geography based on power relationships that, in geographic science, contribute to unveil the uneven phenomena of waste collection and recycling. The main understanding is that such phenomena influence the practice of social subjects, who have their lives marked by the excluding and exploitative functioning of labor in a capitalist system of production. Therefore, this study seeks to address recycling, not only as a social relationship but as a production network composed of several actors performing different functions in the production of recycled materials. It also discusses the direct relationship between waste picking and precariousness of this work, which classifies the pickers, protagonists in the production maintenance, as the weakest link in the hierarchy, which is also composed of scrap buyers, intermediaries, and entrepreneurs in the processing industry. To achieve these purposes, SciELO, CAPES, and Google Scholar databases were surveyed, considering and focusing on studies that mainly addressed the precariousness of recyclable material collectors' work in a capitalist production system. Furthermore, we discussed studies by economic geography theorists who went deeper into the capitalist logic, such as Harvey (2011) and Smith (1988), and on social scholars who stood out regarding the concept of networks, such as Rosado (2009) and Santos (2006). In the end, it was concluded that, although these workers represent the weakest link in the recycling production network or the "garbage game", if it were not for them, the network would not exist as it is today, especially in the Brazilian recycling context.

Cet article apporte une revue bibliographique de certaines théories économiques basées sur des relations de pouvoir qui, dans le domaine de la science géographique, contribuent à dévoiler les phénomènes de picking et de recyclage. L'orientation principale est que ces phénomènes consistent en la pratique de sujets sociaux dont la vie est marquée par le fonctionnement exclusif et exploitant du travail dans le système de production capitaliste. Dans cette optique, ce travail cherche à réfléchir sur le recyclage en tant que réseau de production, et pas seulement de relations sociales, composé de plusieurs acteurs qui exercent différentes fonctions dans la production de matériaux recyclés. Il aborde également la relation directe entre ramasseur de déchets et précarité de l'emploi, qui fait des ramasseurs, protagonistes du maintien de la production, le maillon le plus fragile de la hiérarchie également composée d'acheteurs de ferraille, d'intermédiaires et de commerçants de l'industrie de la transformation. Pour remplir ces objectifs, il fait partie d'une enquête menée dans des bases de données bibliographiques telles que SciELO, CAPES Periodicals et Google Academic, dans laquelle des recherches ont été envisagées et considérées comme des productions qui traitent principalement du travail précaire du collectionneur de matières recyclables dans la production capitaliste. système. En outre, des recherches menées par des théoriciens de l'économie qui se sont plongés dans la logique capitaliste, parmi lesquels Harvey (2011) et Smith (1988), et des chercheurs en sciences sociales qui se sont lancés dans le concept de réseau, tels que Rosado (2009) et Santos (2006), ont fait l'objet de recherches. .). Il conclut que, dans le même temps que les travailleurs représentent le maillon le plus fragile du réseau de production de recyclage, ou le «jeu de la poubelle», sans eux le réseau n'existerait pas tel quel, notamment dans le contexte du recyclage brésilien.

Este artículo es una revisión bibliográfica de algunas teorías de la geografía económica basadas en las relaciones de poder que, en la ciencia geográfica, contribuyen a develar los fenómenos desiguales de recogida y reciclaje de residuos. El entendimiento principal es que tales fenómenos 
influyen en la práctica de sujetos sociales, los cuales tienen su vida marcada por el funcionamiento excluyente y explotador del trabajo en un sistema de producción capitalista. Por lo tanto, este estudio busca abordar el reciclaje, no solo como una relación social sino como una red de producción compuesta por varios actores que desempeñan diferentes funciones en la producción de materiales reciclados. También se analiza la relación directa entre la recolección de residuos y la precariedad del trabajo, lo que clasifica a los recolectores, protagonistas en el mantenimiento de la producción, como el eslabón más débil de la jerarquía, que también está compuesta por compradores de chatarra, intermediarios y empresarios de la industria procesadora. Para lograr estos propósitos, se recolectaron datos en las bases SciELO, CAPES y Google Académico, considerando y buscando estudios que abordaran principalmente la precariedad del trabajo de recolectores de materiales reciclables en un sistema de producción capitalista. Además, se abordaron los estudios de teóricos de la geografía económica que profundizaron en la lógica capitalista, como Harvey (2011) y Smith (1988), y de académicos sociales que se destacaron en el concepto de redes, como Rosado (2009) y Santos (2006).Al final, se concluyó que, aunque estos trabajadores representan el eslabón más débil de la red de producción de reciclaje, o del "juego de la basura", si no fuera por ellos, la red no existiría como es hoy día, especialmente en el contexto brasileño de reciclaje.

\section{ÍNDICE}

Mots-clés: Théories économiques. Développement inégal. Réseau de production.

Keywords: Economic theories. Uneven development. Production network.

Palavras-chave: Teorias econômicas. Desenvolvimento desigual. Rede de produção.

Palabras claves: Desarrollo desigual., Red de producción., Teorías económicas.

\section{AUTORES}

\section{UILMER RODRIGUES XAVIER DA CRUZ}

Doutorando em Geografia pela Universidade Federal de Minas Gerais (UFMG) e Departamento de Ciências Sociais da Universidade Nacional de Quilmes (UNQ) em regime cotutela. Bolsista de doutorado da Fundação de Amparo à Pesquisa do Estado de Minas Gerais (FAPEMIG) (2020). Mestre em Geografia pela Universidade do Estado do Rio de Janeiro (UERJ) (2019), Graduação em Geografia - Ênfase em Sistemas de Informações Geográficas pela Pontifícia Universidade Católica de Minas Gerais (PUC-MG) (2008). Atualmente é pesquisador do Grupo de Pesquisa Interdisciplinar e Extensão Lélia Gonzalez - (FURG) e do Grupo de Estudos e Pesquisas em Resíduos Sólidos - (UEMG). Interesse de investigação: Rede de reciclagem, cadeia globais, circuitos da economia urbana, produção social do trabalho, narrativas do poder e espaço, políticas públicas de coleta seletiva, gestão integrada de resíduos sólidos, tecnologias sociais para gestão integrada de resíduos sólidos, economia do conhecimento. Responsável pelo desenvolvimento e implantação do software CATAsig, PLACAR DA RECICLAGEM e por ministrar cursos, palestras, capacitações em várias cooperativas de catadores no estado da Bahia, São Paulo, Rio de Janeiro e Minas Gerais. E-mail: uilmer@ufmg.br

\section{LUIZ JARDIM DE MORAES WANDERLEY}

Professor do Departamento de Geografia da Universidade Federal Fluminense - UFF e do Programa de Pós-Graduação em Geografia da Faculdade de Formação de Professores da Universidade do Estado do Rio de Janeiro - UERJ-FFP. Geógrafo, com graduação em Bacharel e 
Licenciatura em Geografia pela Universidade Federal do Rio de Janeiro (2006/2007), mestrado em Geografia (2008) e Doutorado em Geografia na mesma instituição (2015) com estágio de bolsa sanduíche na Vrije Universiteit Amsterdam - VU (2012/2013). Atualmente é pesquisador do Grupo de Pesquisa e Extensão Política, Economia, Mineração, Ambiente e Sociedade - PoEMAS.

\section{LUÍS HENRIQUE LEANDRO RIBEIRO}

Bacharel em Geografia pela Universidade Estadual de Campinas - Unicamp (2005), graduado em Licenciatura pela Universidade Estadual de Campinas - Unicamp (2006) e Doutor em Geografia pela Universidade Estadual de Campinas - Unicamp (2015). Ganhou o Prêmio Capes de Tese 2016 na área de Geografia. Pós-doutor pelo Programa de Pós-graduação em Geografia da Faculdade de Formação de Professores da Universidade do Estado do Rio de Janeiro (FFP/UERJ) 2015-2019. Desde 2015 é integrante do Núcleo de Pesquisa e Extensão: Urbano, Território e Mudanças Contemporâneas (Nutemc/FFP/UERJ) e colaborador do projeto Brasil Saúde Amanhã de Prospecção Estratégica do Sistema Único de Saúde na Fundação Oswaldo Cruz (Fiocruz). De 2018 a 2020 foi Professor Substituto de Geografia Humana no Departamento de Geografia da Universidade Federal do Rio de Janeiro (UFRJ). Desde 2020 é Professor Adjunto no Departamento de Geografia da Faculdade de Formação de Professores da Universidade do Estado do Rio de Janeiro (DGEO/FFP/UERJ). Tem experiência em pesquisa, ensino e extensão na área de Geografia, com ênfase em Geografia Regional, Urbana, Política e Econômica, atuando principalmente nos temas: circuitos da economia urbana, circuitos espaciais produtivos, mercados institucionais e populares, planejamento territorial e urbano-regional, políticas públicas, sistemas e políticas de saúde, desigualdade socioespacial, conflitos territoriais, povos e comunidades tradicionais. 